\title{
FORMULATION AND EVALUATION OF IN-SITU GEL CONTAINING LINEZOLID IN THE TREATMENT OF PERIODONTITIS
}

\author{
INAYATHULLA ${ }^{1 *}$, PRAKASH GOUDANAVAR ${ }^{1}$, MOHAMMAD ALI ${ }^{2}$, SHAHID UD DIN WANI ${ }^{3}$, NAGARAJA \\ SREEHARSHA ${ }^{4}$
}

${ }^{* 1}$ Department of Pharmaceutics, Sri Adichunchanagiri College of Pharmacy, B. G. Nagara, Karnataka 571448, ${ }^{2}$ Department of Pharmacology, Farooqia College of Pharmacy, Tilak Nagar, Mysore 570001, ${ }^{3}$ Department of Pharmaceutics, CT Institue of Pharmaceutical Sciences, Jalandhar, Punjab 144020, ' ${ }^{4}$ Department of Pharmaceutical Sciences, College of Clinical Pharmacy, King Faisal University, Saudi Arabia, ${ }^{4}$ Department of Pharmaceutics, Vidya Siri College of Pharmacy, off Sarjapura Road, Bengaluru 560035, Karnataka, India *Email: inaythmehdi@gmail.com

Received: 23 Dec 2020, Revised and Accepted: 27 Feb 2021

\section{ABSTRACT}

Objective: The intent to prepare and evaluate Linezolid in-situ gel in the treatment of periodontitis.

Methods: pH-sensitive in-situ gel was formed by the cold method using a varying concentration of the drug, carbopol 934P and hydroxypropyl methylcellulose (HPMC) and carbopol 934P and sodium carboxy methylcellulose (CMC) (1:1,1:1.5,1:2,1:2.5). An optimized batch was selected based on gelling time and gelling capacity. The prepared in-situ gels were evaluated for appearance, $\mathrm{pH}$, gelling capacity, viscosity, in vitro release studies, rheological studies, and finally, was subjected to drug content estimation and antibacterial activity test.

Results: FTIR study shows drug and physical mixture were compatible with each other. The rheology of formulated in-situ gel exhibited a pseudoplastic flow pattern. this may be because when polymer concentration was increased the prepared formulations become more viscous and in turn delayed the drug release and from the prepared formulation, LF4 and SF4 have polymer concentrations i. e, $0.9 \%$ carbopol and sodium CMC showed drug release up to $12 \mathrm{~h}$.

Conclusion: When carbopol is appropriately mixed with other suitable polymers it forms an in-situ gel-forming system that was substantiated by the property to transform into stiff gels when the $\mathrm{pH}$ is increased. The in-situ gel was prepared using a combination of carbopol-HPMC and carbopol-Na CMC The formulations LF1 to SF4 showed high linearity (R2 $=0.490-0.682)$, indicating that the drug was released from the prepared in-situ gel by the diffusion-controlled mechanism. Thus, the formulation of batches LF4 and SF4 containing carbopol: HPMC and carbopol: NaCMC in 1:2 ratios were considered as optimum formulation based on optimum viscosity, gelling capacity and to extend the in vitro drug release.

Keywords: Linezolid, In-situ gel, Periodontal disease

(C) 2021 The Authors. Published by Innovare Academic Sciences Pvt Ltd. This is an open access article under the CC BY license (https://creativecommons.org/licenses/by/4.0/) DOI: https://dx.doi.org/10.22159/ijap.2021v13i3.40604. Journal homepage: https://innovareacademics.in/journals/index.php/ijap

\section{INTRODUCTION}

Periodontal diseases are mainly of bacterial etiology in the initiation and progression of periodontal diseases. The treatment goal is in the reduction of infection and inflammation, which can be achieved using adjunctive drugs such as anti-microbial agents and anti-inflammatory agents [1]. The World Health Organization (WHO) has reported that antibiotic resistance causes about 700,000 deaths each year and that this number will reach 10 million globally by 2050 if no effective intervention becomes available (WHO, 2014) [2]. Linezolid is a new class of antibiotic, the oxazolidinones, which is used in the therapy of infections caused by aerobes and anaerobes susceptible organisms methicillin and vancomycin-resistant [3]. It has been demonstrated that Linezolid is superior to vancomycin in terms of antipyretic and anti-inflammatory properties [4]. A variety of pharmacological agents has been studied in the therapy of periodontitis. These include anti-inflammatory drugs, biphonates, and antimicrobials. Controlled local delivery of the antimicrobial anti-inflammatory agents was consequently developed and are effective in the concentration of the drug in the periodontal pocket for prolong periods than systemically delivered methods [5] Articulated pH-triggered system of in-situ gel containing carbopol as in situ gel-forming system has a property of transforming sol into a gel when the $\mathrm{pH}$ is increased. Viscosity improver Hydroxy Propyl Methyl Cellulose (HPMC) is added to achieve sustained drug release in periodontal pocket [6]. So intent is to develop and deliver new treatments for periodontal disease that target drugresistant bacteria, which caused the big threat. Hence challenge was to articulate Linezolid in-situ periodontal gel which sustains for a longer duration of action by remedying periodontal disease.

\section{MATERIALS AND METHODS}

Drug characterization study

Infra-red (IR) spectroscopy study: an fourier transform

IR spectrum of the Linezolid and polymers was obtained on a Shimadzu Corporation, Japan. A multi particulate form drug prepared with Potassium bromide (Spectroscopic Grade) using hydraulic pellet press at a pressure of 7-10 tones. The scanning range was 400 to $4000 \mathrm{~cm}^{-1}$ and the resolution was $1 \mathrm{~cm} \mathrm{[6].}$

\section{Preparation of in-situ gel procedure}

In-situ gels were formed by cold method using varying concentration of drug, carbopol 934P and hydroxypropyl methylcellulose (HPMC) (LF1, LF2, LF3 and LF4) and carbopol 934P and sodium carboxy methyl cellulose (NaCMC) (SF1=1:1, SF2=1.15, SF3=1:2, $S F 4=1: 2.5$ ). Optimized batch was selected based on gelling time and gelling capacity. Formulations containing drug and polymer ratios are coded as $L F 1=1: 1, L F 2=1.15, L F 3=1: 2, L F 4=1: 2.5$ SF1=1:1, $S F 2=1.15$, $S F 3=1: 2, \quad S F 4=1: 2.5$. Experimentation was done using different concentrations of drug and polymers to obtain the desirable concentration of formulation for the gelling. Dispersion of NaCMC and carbopol 934P was added to aqueous solution of sodium citrate $(0.19 \% \mathrm{w} / \mathrm{v})$ while stirring heated to $92{ }^{\circ} \mathrm{C}$ then cooling it to under $38{ }^{\circ} \mathrm{C}$ then calcium chloride $(0.06 \% \mathrm{w} / \mathrm{v})$ was mixed into the solutions. Linezolid was dissolved in propylene glycol separately. Mixture of drug and propylene glycol was added in the polymeric solution. The mixture was placed on magnetic stirrer for thorough mixing. Methylparaben (MP) and propylparaben (PP) were added as preservatives. Finally the triethanolamine was added to neutralize 
in-situ gel and air bubbles were removed from ready to use solution by allowing it to stand for $2 \mathrm{~h}$ [7].

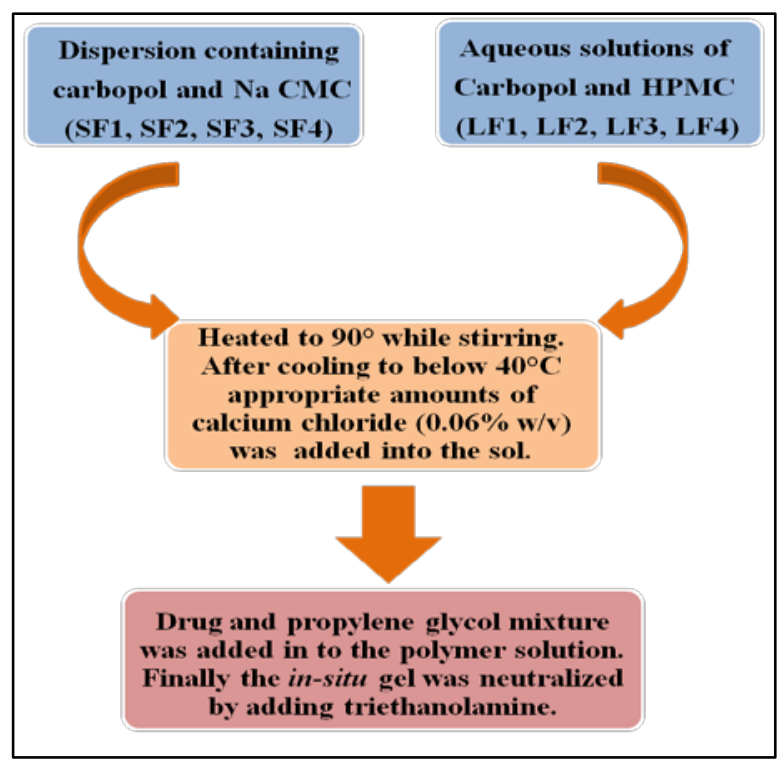

Fig. 1: Manufacturing steps involved in in-situ gel technique

\section{Evaluation of in-situ gel}

\section{Appearance}

Formulated preparations clarity was observed by visual inspection.

\section{Determination of $\mathrm{pH}$}

$\mathrm{pH}$ of formulations was determined using $\mathrm{pH}$ digital meter instrument

\section{Gelling capacity}

The gelation capacity was found by the visual method by using dye formulated solutions were colored. Gelation capacity was determined by placing $3 \mathrm{ml}$ of $\mathrm{pH} 6.8$ phosphate buffer in a $10 \mathrm{ml}$ test tube ad maintained at body temperature. $1 \mathrm{ml}$ of colored formulated preparation was added to the phosphate buffer. As the formulation mixed with prepared phosphate buffer, the formulation was quickly transformed into gel [8].

\section{Gelation temperature}

Magnetic bead and $10 \mathrm{ml}$ of sample solution were taken in a vial which was kept in a water bath. The heating of the solution was done by stirring at $1^{\circ} / \mathrm{min}$. Gelation was considered when the magnetic bead stopped moving at a particular temperature and noted down as gelation temperature [8].

\section{Gelation time}

Test tube containing $2 \mathrm{ml}$ of linezolid in-situ gel was kept in a water bath and the temperature was raised slowly by heating and allowed to stand to equilibrate for fresh settlement. Gelation of the sample was examined; gelation took place when the meniscus upon tilting through $90^{\circ}$ would no longer move [8].

\section{Spreadability}

The formulated gel and its ability to spread was determined for $48 \mathrm{~h}$ after preparation, it is measured by spreading one gram gel in between plates made up of glass for $1 \mathrm{~min}$. The weight of the top glass plate was standardized at $125 \mathrm{~g}$. The mathematical formula expressed as:

$$
\mathrm{S}=\mathrm{M}^{*} \mathrm{~L} / \mathrm{T}
$$

Where $\mathrm{L}$ is the length of the glass slide, $\mathrm{M}$ is mass weight tied up to the slide, and $\mathrm{T}$ is the time taken. Homogeneity of the formulated gel was inspected visually [8].

\section{Syringeability}

All formulated gel was transferred into an identical 5cc (cubic centimeter) plastic syringe with a 21 gauge needle to constant volume $(1 \mathrm{ml})$. The formulated gel was easily pass through from the syringe considered as pass and if not pass through as fail [9].

\section{Drug content estimation}

One $\mathrm{ml}$ of the different formulated in-situ gel was added to a vial containing $5 \mathrm{ml}$ of distilled water and equilibrated at $37^{\circ} \mathrm{C}$ and the formation of the gel was observed visually. Once gel formed, formulations were taken into dialysis tubes. These tubes were placed in a transparent cup contained $50 \mathrm{ml}$ of distilled water and formulated gel was dialyzed for half a minute at $50 \mathrm{rpm}$ and this medium was changed with new distilled water to confirm complete removal of the entrapped drug. The concentration of all these solutions was found spectrophotometrically at $250 \mathrm{~nm}$, after acceptable dilution and filtration using distilled water as blank [9].

\section{Viscosity and rheological studies}

To determine the rheology of Linezolid in-situ gel spindle number LC of Brookfield digitalized viscometer was used. The in-situ gel viscosity was determined at various angular velocities at $25{ }^{\circ} \mathrm{C}$. A distinctive run comprised of changes in the angular velocity from 10 to $60 \mathrm{rpm}$. The viscosity measures were performed prior to gelling and after gelling [9].

\section{In vitro release kinetics studies}

The kinetic study of drug release from Linezolid in-situ gel was interpreted, after obtaining data from in vitro release of drug study and it was fit into various standard models including first and zero orders. The $\mathrm{r}^{2}$ values obtained by comparison and the better model fitted was selected [10].

\section{In vitro diffusion studies}

The release of drug profile from Linezolid in-situ gel was performed by using Franz diffusion cell (capacity $25 \mathrm{ml}$ ). One gram of linezolid formulated in-situ gel was placed in the donor compartment and 25 $\mathrm{ml}$ of $\mathrm{pH} 6.8$ dissolution medium (simulated salivary $\mathrm{pH}$ ) in the receptor compartment. In the middle of the receptor and donor compartment chicken cheek, the mucous membrane is placed. Sols were added to it from above so that when it comes in contact with the saliva, fluid gets transformed into gel form. This assembly was kept on the magnetic stirrer, which is controllable by thermostatic manner. The temperature of the medium was kept at $37^{\circ} \mathrm{C} \pm 0.5^{\circ} \mathrm{C} .1$ $\mathrm{ml}$ of the sample was removed at prior determined rate $0.5 \mathrm{~h}$ to $12 \mathrm{~h}$ interval and a fresh medium of the same volume was replaced. Removed samples were diluted to $10 \mathrm{ml}$ in a volumetric flask with the same buffer medium and analyzed using an Ultraviolet spectrophotometer at $250 \mathrm{~nm}$ using blank. The drug content was determined by using an equation obtained from the standard curve. The percentage of cumulative drug release (\% CDR) was calculated [9-16].

\section{Antibacterial activity}

The growth of microbial bacteria was measured by the concentration of antibiotics present and comparison of this with standard preparation of antibiotic that produced by known concentration. The microbiological assay carried out by serial dilution method was employed [12, 13]. Test organism recommendation for linezolid is Staphylococcus aureus [14]

\section{RESULTS AND DISCUSSION}

\section{Drug-polymer interaction studies}

There is no significant interaction was observed between pure drug and polymer mixture from FTIR spectrum are in fig. 1 and 2. 


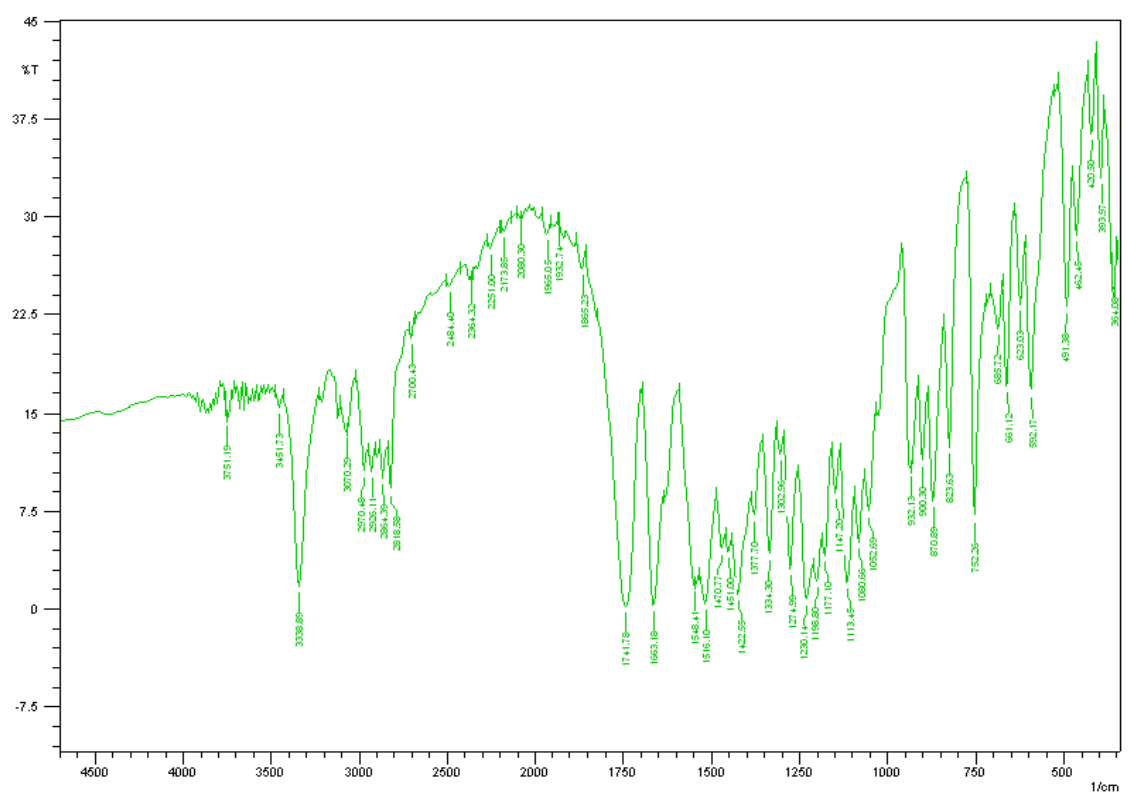

Fig. 2: FTIR spectrum of the linezolid

FTIR spectrum of drug and polymeric mixture

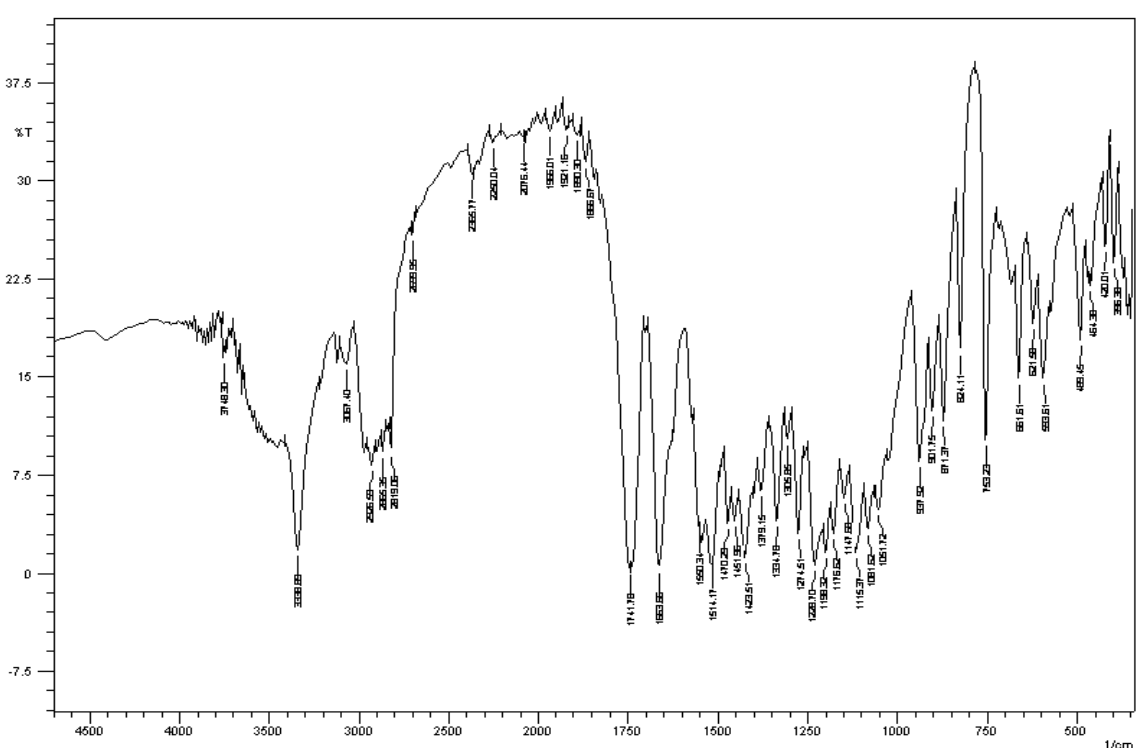

Fig. 3: FTIR spectrum of the linezolid and polymers

\section{Appearance}

All formulated in-situ gel is shown clearness.

\section{Determination of $\mathrm{pH}$}

The measured $\mathrm{pH}$ in meter was found to be in the range of 4 to 7.5 , which is the required range to formulate in-situ gel. The $\mathrm{pH}$ of formulated linezolid in-situ gel was adjusted in the range 6.2 to 7 by using triethanolamine. The measured $\mathrm{pH}$ is shown in table 2.

\section{Gelation temperature and gelation time}

For the selection of a proper concentration of polymers (carbopol and sodium CMC), various solutions of polymers of different concentrations ranging from $0.6-0.9 \%$ were prepared and optimized concentration was prepared based on gelation temperature and gelation time. The temperature of gelation ranging from 34 to $37^{\circ} \mathrm{C}$ is considered as suitable for in-situ gel in periodontal disease, which is nothing but gel should be in solution form at normal temperature and the oral cavity form a gel phase. If the temperature of gelation is less than $33{ }^{\circ} \mathrm{C}$ of the solution, then gelation occurs at room temperature, which leads to difficulty in administering the formulation. If the gelling temperature is higher than $35^{\circ} \mathrm{C}$ of in-situ gel formulation, the gel stays in a liquid form at body temperature, leads to leakage of formulation from the periodontal pocket. The gelation temperature of linezolid in-situ gel was found by visual inspection method within the range of 34 to $37^{\circ} \mathrm{C}$. The temperature of gelation was dependent on the polymer concentration used; the results are depicted in table 2. Formulation LF4 and SF4 showed rapid gelation i.e. at $5.36 \mathrm{~min}$ and $8.28 \mathrm{~min}$, respectively, as this formulation contains the highest concentration of polymers. This study revealed that when polymer concentration increases, there was a decrease in gelation time and gelation temperature. 
Formulations LF1, SF1 and SF2 were discarded from the study, as these formulations do not form gel up to $45^{\circ} \mathrm{C}$. Formulation LF4, containing $0.9 \%$ carbopol showed the lowest gelation time i.e. 5.37 min compared to formulation SF4 containing the same concentration of $\mathrm{Na}$ CMC i.e. 8.28. In our study, formulations containing carbopol showed less gelation time compared to formulations containing sodium CMC.

\section{Drug content estimation}

All formulations of Linezolid in-situ gel were analyzed for drug content spectrophotometrically at $250 \mathrm{~nm}$. Prepared in-situ gels exhibited fairly uniform drug content. This ensures an intended drug delivery to the site after administration. All prepared in-situ gels formulations' drug content as shown in table 4 and found to be in the range of 96.80 to $98.42 \%$. the data depicts there is no significant loss of drug in any formulation during manufacture.

\section{Syringeability}

Syringeability test showed that prepared in-situ gel formulations were easily injectable at room temperature $\left(25^{\circ} \mathrm{C}\right)$, through 21 gauge needle. This facilitates the injection of sol directly into the periodontal pocket.

Table 1: Characteristics of various formulations

\begin{tabular}{llllll}
\hline Code & Drug: polymer & pH adjusted & $\begin{array}{c}\text { Gelation } \\
\text { temp }\left({ }^{\circ} \mathbf{C}\right)\end{array}$ & Gelation & $\begin{array}{c}\text { Gelation } \\
\text { time }(\mathbf{m i n})\end{array}$ \\
\hline LF1 & $1: 1$ & 6.8 & 46 & No gelation & -- \\
LF2 & $1: 1.5$ & 6.5 & 37 & Gelation after few minutes & 97.54 \\
LF3 & $1: 2$ & 6.2 & 35 & Immediate and stable for few hours & 96.80 \\
LF4 & $1: 2.5$ & 6.2 & 34 & Immediate and stable for extended period & 5.22 \\
SF1 & $1: 1$ & 6.9 & 45 & No gelation & 96.99 \\
SF2 & $1: 1.5$ & 7.5 & 46 & No geiation & -- \\
SF3 & $1: 2$ & 6.5 & 37 & After few minutes & -- \\
SF4 & $1: 2.5$ & 7.1 & 35 & Immediate and stable for few hours & 98.42 \\
\hline
\end{tabular}

\section{Spreadability studies}

The spreadability studies results shown in table 2 revealed that spreadability decreases when polymers concentration of in-situ gel formulation increases [17]. Table 2 depicts the data that indicates that the increase in the concentration of any of the gelling agents in the in-situ gels formulations decreases its spreadability. Shorter the time taken to separate 2 slides better will be the spreadability. The spreadability of all prepared in-situ gel formulations was found to be in the range of 12.70-21.04 $\mathrm{gm} \cdot \mathrm{cm} / \mathrm{sec}$. Formulation LF4 containing the highest concentration of carbopol was less spreadable $(12.70 \mathrm{gm} \cdot \mathrm{cm} / \mathrm{sec})$ when compared to the same concentration of Sodium CMC i.e. formulation SF4 $(15.00 \mathrm{gm} \cdot \mathrm{cm} / \mathrm{sec})$.

Table 2: Spreadability studies results

\begin{tabular}{lllll}
\hline Formulation & Weight tied to the upper slide (g) & Length of the glass slide (cm) & Time (sec) & Spreadability (gm'cm/sec) \\
\hline LF1 & 125 & 8.3 & 60 & 60 \\
LF2 & 125 & 7.8 & 60 & $17.29 \pm 0.3$ \\
LF3 & 125 & 7.4 & 60 & $15.41 \pm 0.2$ \\
LF4 & 125 & 6.1 & 60 & $12.70 \pm 0.3$ \\
SF1 & 125 & 10.1 & 60 & $1.04 \pm 0.2$ \\
SF2 & 125 & 8.6 & 60 & $17.91 \pm 0.1$ \\
SF3 & 125 & 7.9 & 60 & $16.45 \pm 0.3$ \\
SF4 & 125 & 7.2 & $15.00 \pm 0.2$ \\
\hline
\end{tabular}

(Values represent mean $\pm \mathrm{SD}, \mathrm{n}=3$ )

\section{Viscosity study of in-situ gel formulations}

The viscosity of prepared linezolid in-situ gel shear rate was increased as the viscosity of gel decreased in both prior gelling and after gelation cases. Results of viscosity studies showed that viscosity of prepared formulation was drastically increased to a 4-fold increase in the viscosity of prepared after gelation. The viscosity of the prepared insitu gel was the concentration-dependent of the gel base; on increasing the concentration of polymer, the viscosity of the gel was increased (table 4). Rheological evaluation of selected formulation exhibited pseudoplastic flow before and after gelation (fig. 4 and 5). Further, the formulations were liquid neutral $\mathrm{pH}$ and underwent rapid gelation when the $\mathrm{pH}$ was at 6.8 . The viscosity of the prepared formulation contributed to the product adhesiveness, reflecting the importance of product rheology on this parameter. Additionally, the gel formed insitu should maintain its integrity without dissolving or eroding for a prolonged period. These results are in accordance with the finding of Biswas and Yellanki et al. [18, 19].

Table 3: Viscosity before gelation

\begin{tabular}{|c|c|c|c|c|c|c|c|c|}
\hline \multicolumn{9}{|c|}{ Viscosity before gelation (cps) } \\
\hline \multicolumn{9}{|c|}{ Formulation } \\
\hline RPM & LF1 & LF2 & LF3 & LF4 & SF1 & SF2 & SF3 & SF4 \\
\hline 10 & $985 \pm 2.2$ & $1055 \pm 2.4$ & $1070 \pm 2.6$ & $1127 \pm 2.3$ & $976 \pm 2.5$ & $1020 \pm 2.0$ & $1065 \pm 2.3$ & $1090 \pm 2.6$ \\
\hline 20 & $750 \pm 1.9$ & $765 \pm 0.2$ & $786 \pm 1.6$ & $795 \pm 1.4$ & $730 \pm 1.7$ & $750 \pm 1.1$ & $770 \pm 1.3$ & $805 \pm 1.2$ \\
\hline 30 & $581 \pm 1.4$ & $595 \pm 1.7$ & $600 \pm 1.3$ & $608 \pm 1.5$ & $560 \pm 1.2$ & $575 \pm 1.1$ & $580 \pm 1.4$ & $610 \pm 1.5$ \\
\hline 40 & $334 \pm 1.2$ & $343 \pm 1.3$ & $354 \pm 1.2$ & $369 \pm 1.5$ & $325 \pm 1.7$ & $310 \pm 1.3$ & $340 \pm 1.5$ & $385 \pm 1.3$ \\
\hline 50 & $177 \pm 1.5$ & $165 \pm 1.8$ & $180 \pm 1.4$ & $206 \pm 1.1$ & $160 \pm 1.3$ & $158 \pm 1.2$ & $170 \pm 1.6$ & $206 \pm 1.4$ \\
\hline 60 & $98 \pm 1.5$ & $105 \pm 1.2$ & $112 \pm 1.4$ & $117 \pm 1.3$ & $102 \pm 1.5$ & $110 \pm 1.4$ & $120 \pm 1.2$ & $125 \pm 1.6$ \\
\hline
\end{tabular}

(Values represent mean $\pm \mathrm{SD}, \mathrm{n}=3$ ) 


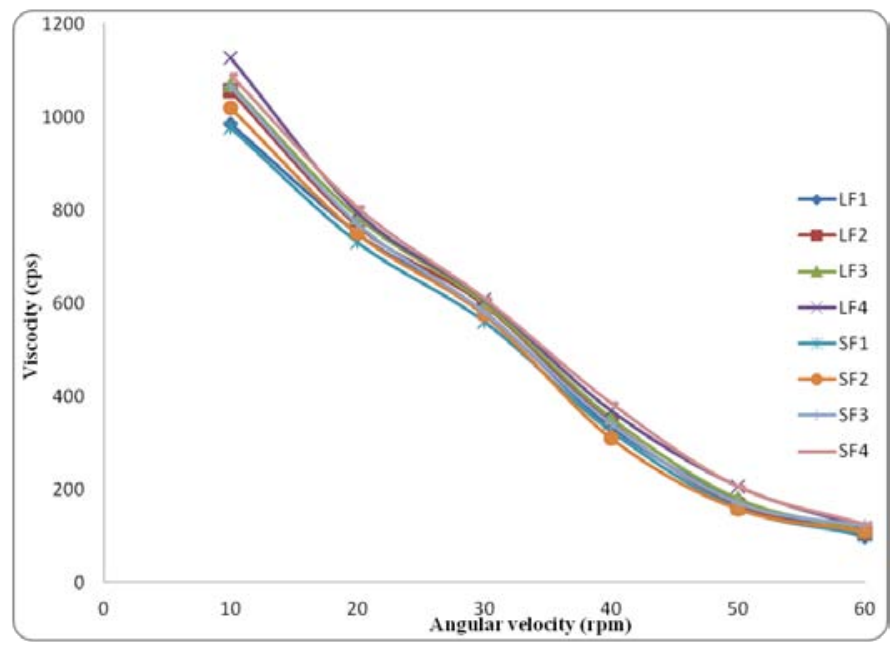

Fig. 4: Rheological study of prepared formulation before gelling

Table 4: Viscosity after gelation

\begin{tabular}{|c|c|c|c|c|c|c|c|c|}
\hline \multicolumn{9}{|c|}{ Viscosity after gelation (cps) } \\
\hline \multicolumn{9}{|c|}{ Formulation } \\
\hline RPM & LF1 & LF2 & LF3 & LF4 & SF1 & SF2 & SF3 & SF4 \\
\hline 10 & $3880 \pm 1.5$ & $4068 \pm 1.3$ & 4225 & $4633 \pm 1.3$ & 3760 & $4015 \pm 1.3$ & $4460 \pm 2.6$ & $4570 \pm 1.8$ \\
\hline 20 & $2850 \pm 1.7$ & $3387 \pm 2.6$ & 3470 & $3550 \pm 2.6$ & 2742 & $3260 \pm 1.6$ & $3380 \pm 2.6$ & $3430 \pm 1.3$ \\
\hline 30 & $2270 \pm 1.3$ & $2380 \pm 1.7$ & 2450 & $2538 \pm 1.7$ & 2229 & $2275 \pm 1.7$ & $2348 \pm 1.3$ & $2450 \pm 1.7$ \\
\hline 40 & $1685 \pm 1.3$ & $1610 \pm 1.6$ & 1715 & $1761 \pm 1.3$ & 1625 & $1570 \pm 1.2$ & $1630 \pm 1.6$ & $1690 \pm 1.6$ \\
\hline 50 & $970 \pm 1.6$ & $995 \pm 1.3$ & 1025 & $1059 \pm 1.6$ & 862 & $965 \pm 1.3$ & $1015 \pm 1.3$ & $1025 \pm 1.2$ \\
\hline 60 & $565 \pm 1.3$ & $530 \pm 1.3$ & 505 & $487 \pm 1.5$ & 575 & $560 \pm 1.4$ & $546 \pm 1.3$ & $520 \pm 1.3$ \\
\hline
\end{tabular}

(Values represent mean $\pm \mathrm{SD}, \mathrm{n}=3$ )

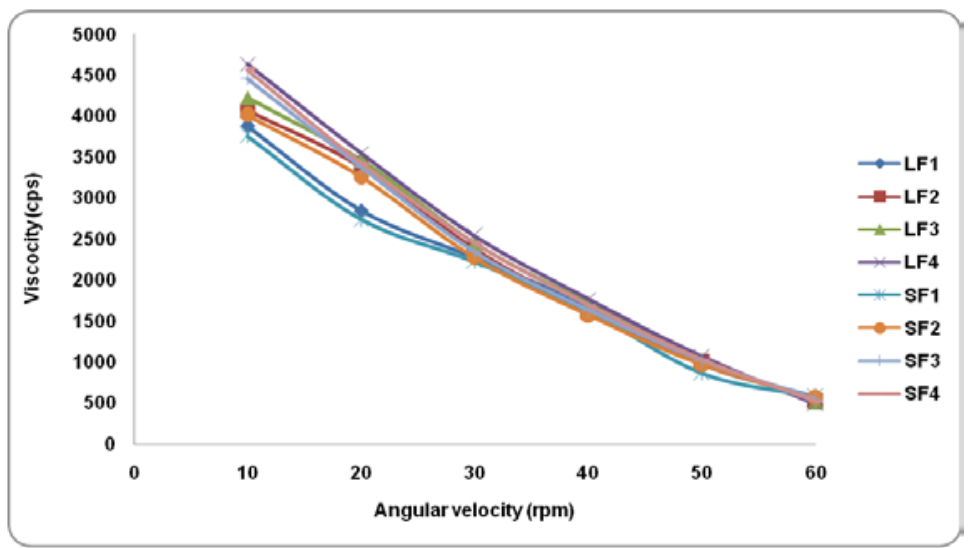

Fig. 5: Rheological study of prepared formulation after gelation

\section{In vitro release kinetics studies}

- The obtained results of all the formulations were best described by the Higuchi release kinetics model, as the plots showed higher linearity $\left(\mathrm{r}^{2}=0.994-0.996\right)$ in comparison to zero-order $\left(\mathrm{r}^{2}=0.894\right.$ $0.912)$ and first-order $\left(r^{2}=0.917-0.942\right)$. The $r 2$ values obtained, by comparison, the better model fitted was selected

- The release exponent (n) value was obtained in the range of 1.161.48, which suggest that formulated linezolid in-situ gel matched with Super-case II transport and the obtained (n) values are greater than 0.89

\section{In vitro diffusion study}

This study was performed for $12 \mathrm{~h}$. During diffusion studies, the polymer concentration effect of in-situ gel formulated was carried out on release pattern. The CDR (cumulative drug released) percentage shown in fig. 9. Results showed the drug was decreased in formulated in-situ gel formulations when polymer concentration was increased this may be because the prepared formulations become more viscous which in turn delayed the release pattern of the drug from the prepared formulation. These outcomes are parallel to interpretations reported earlier by Parhi, Kalia, and Mekkawy et al. [20-22]. This release pattern of drug study reveals almost half of the drug discharges from all formulations within $4.0 \mathrm{~h}$. The drug release from these gels was characterized by the first opening phase of high release up to $4.0 \mathrm{~h}$ and the rest of the drug was liberated at a slower rate in the next phase. This dual-phase drug pattern release is a distinctive feature of matrix diffusion kinetics. Formulation LF1, LF2, LF3, SF1, SF2, and SF3 showed almost $75 \%$ of drug discharges up to 6 hour, whereas formulation LF4 and SF4 with the highest polymer concentration that is $0.9 \%$ carbopol and sodium methylcellulose showed release of the drug up to $12 \mathrm{~h}$, which might be due to higher viscosity and gelation capacity of these prepared formulations based on release studies, formulation LF4 and SF4 was selected for further studies. 
Table 5: Values of release exponent and rate constant

\begin{tabular}{|c|c|c|c|c|c|c|c|}
\hline \multirow[t]{3}{*}{ Formulation code } & \multicolumn{5}{|c|}{ Kinetics models } & \multirow{3}{*}{$\begin{array}{l}\text { Best fit } \\
\text { model }\end{array}$} & \multirow[t]{3}{*}{ Drug release mechanism } \\
\hline & \multirow{2}{*}{$\begin{array}{l}\text { Zero order } \\
\mathbf{R}^{2}\end{array}$} & \multirow{2}{*}{$\begin{array}{l}\text { First order } \\
\mathbf{R}^{2} \\
\end{array}$} & \multirow{2}{*}{$\begin{array}{l}\text { Higuchi } \\
\mathbf{R}^{2} \\
\end{array}$} & \multicolumn{2}{|c|}{ Korsmeyer-peppas } & & \\
\hline & & & & $\mathbf{R}^{2}$ & $\mathbf{n}$ & & \\
\hline LF1 & 0.873 & 0.905 & 0.970 & 0.682 & 1.018 & Higuchi & Super case II \\
\hline LF2 & 0.858 & 0.839 & 0.984 & 0.490 & 1.189 & Higuchi & Super case II \\
\hline LF3 & 0.821 & 0.656 & 0.983 & 0.604 & 1.088 & Higuchi & Super case II \\
\hline LF4 & 0.8580 & 0.885 & 0.994 & 0.547 & 1.012 & Higuchi & Super case II \\
\hline SF1 & 0.909 & 0.909 & 0.983 & 0.534 & 1.053 & Higuchi & Super case II \\
\hline SF2 & 0.847 & 0.796 & 0.975 & 0.520 & 1.083 & Higuchi & Super case II \\
\hline SF3 & 0.943 & 0.866 & 0.978 & 0.472 & 1.192 & Higuchi & Super case II \\
\hline SF4 & 0.851 & 0.894 & 0.987 & 0.680 & 1.005 & Higuchi & Super case II \\
\hline
\end{tabular}

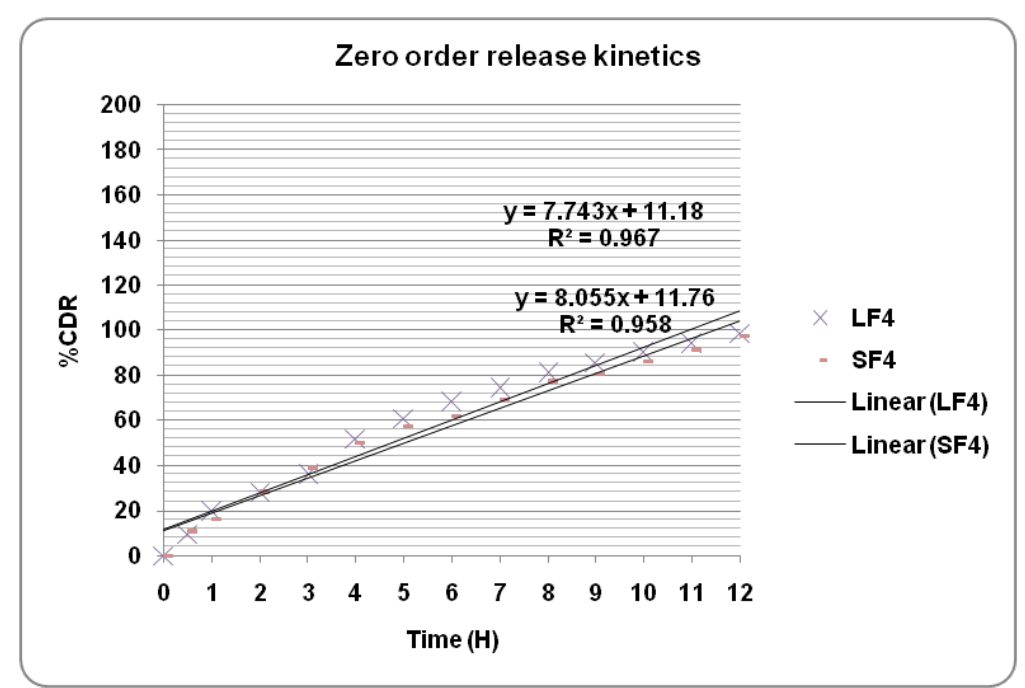

Fig. 6: Comparative zero order release profile of in-situ gel formulation

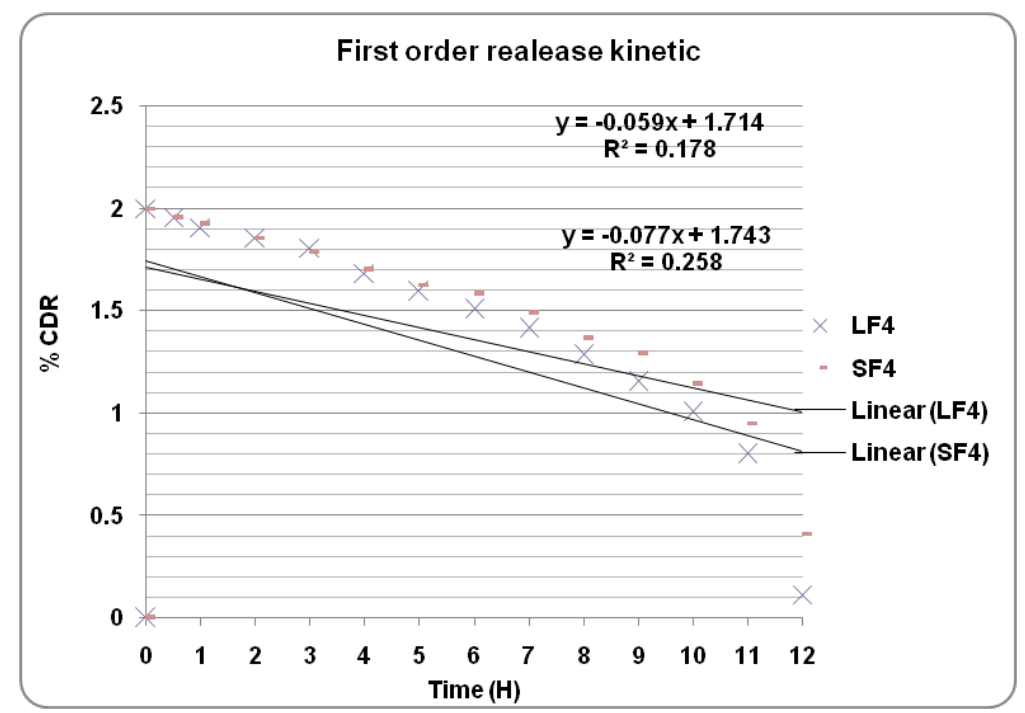

Fig. 7: Comparative first order release profile of in-situ gel formulations

\section{Antibacterial activity}

The activity of three samples was tested for Minimum Inhibitory Concentration (MIC) against Staphylococcus aureus., and they are coded as $\mathrm{X}, \mathrm{Y}$, and $\mathrm{Z}$. $\mathrm{X}=$ formulation $\mathrm{LF} 1, \mathrm{Y}=$ pure sample, $\mathrm{Z}=$ formulation SF4. 250 $\mu$ g concentration of Linezolid drug was added to the standard solution and sample solution. 13 Sterilized test tubes were numbered from 1 to 13 . Linezolid $128 \mu \mathrm{g} / \mathrm{ml}$ of concentration and $1000 \mu \mathrm{l}$ of the solution was transferred from tube no.1 to tube no. 2 by mixing. In a similar manner tube, no. 3 to tube no. 10 prepared to get various concentrations. The final two tubes each contain a thousand microliters of media named as media restrain and another tube as drug restrain. 10 microliters broth of the $S$. aureus was seeded into all the tubes except in negative control and it was kept in an incubator at $37^{\circ} \mathrm{C}$ for up to one day to find its growth. Subsequently, $24 \mathrm{~h}$ later the incubated tubes were observed for growth inhibition and MIC calculated and finally, results were tabulated in table 6 . 


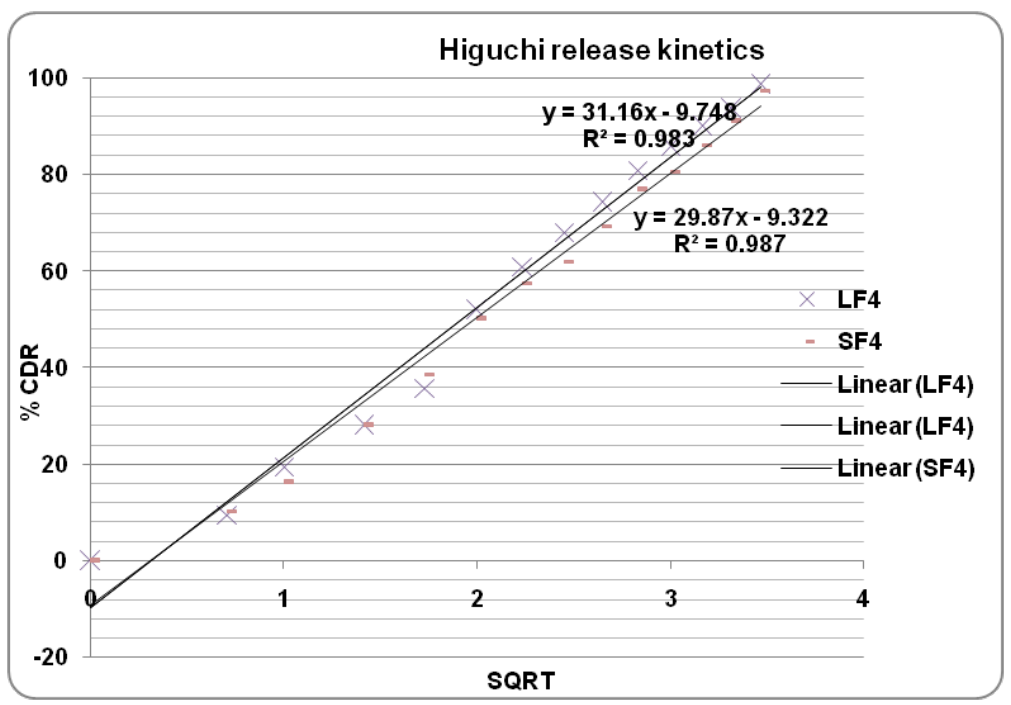

Fig. 8: Comparative higuchi release kinetics of in-situ gel formulations

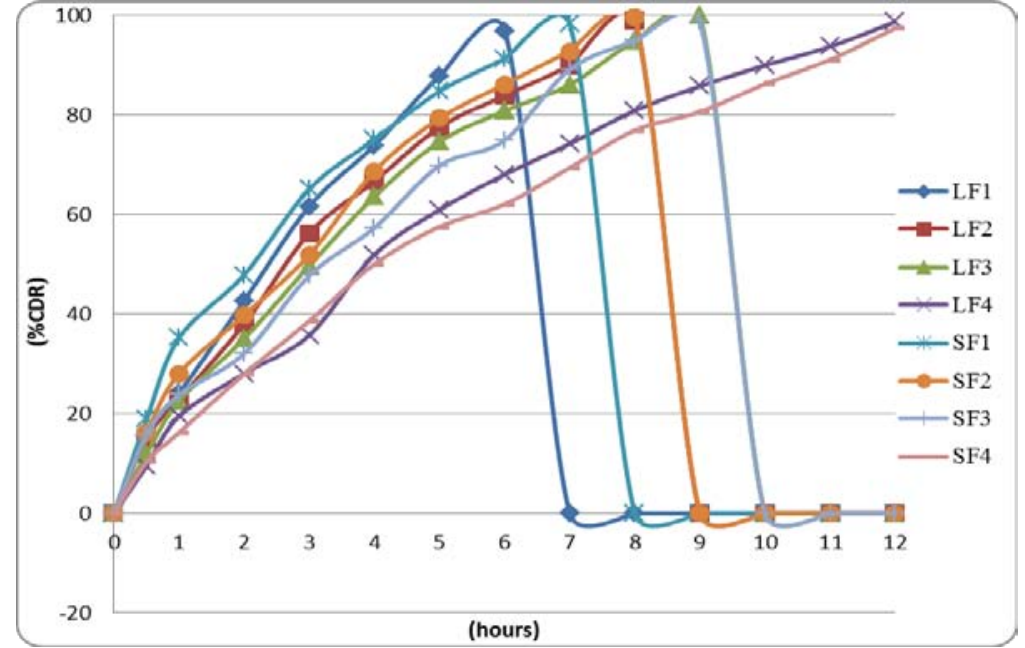

Fig. 9: The in vitro release profiles of linezolid in-situ gels

Table 6: Antibacterial activity test-MIC

\begin{tabular}{llll}
\hline Concentration in mcg/ml & Turbidity in pure drug sample (standard) & Turbidity in LF1 formulation & Turbidity in SF4 formulation \\
\hline 128 & - & - & - \\
64 & - & - & - \\
32 & - & - & - \\
8 & - & - & - \\
4 & - & - & + \\
2 & + & + & + \\
1 & + & + & + \\
0.5 & + & + & + \\
0.25 & + & + & - \\
MR & - & - & + \\
DR & - & + & - \\
PC & + & - & \\
NC & - & - & \\
\hline
\end{tabular}

MR = Media Restrain, DR = Drug Restrain, PC = Positive control, NC = Negativecontrol, $(-)=$ no turbidity (inhibitory),+= turbidity (No inhibitory)

The bactericidal sensitivity test for MIC was done by the serial dilution method. Finally, in drug-containing solutions of standard, sample, LF1, and SF4 formulations the Minimum Inhibitory Concentration was found to be 4 micrograms per $\mathrm{ml}$ and observed that it was in accordant with standard linezolid and no reduction in the prepared formulation efficaciousness. These results are in accordance with the finding of Hiremath SSP et al. [23]. The linezolid in-situ gel formulation is a viable alternative and target drugresistant bacteria which caused big threat for the treatment of periodontal disease. 


\section{CONCLUSION}

This study of the articulated pH-triggered system of in-situ gel containing carbopol as in situ gel-forming system has a property of transforming into a gel when the $\mathrm{pH}$ was increased and Viscosity improver HPMC is included to achieve a sustained drug release pattern in the periodontal pocket. The linezolid in-situ gel is a new treatment for periodontitis that targets drug-resistant bacteria which pose the greatest threat for the treatment was successfully formulated using carbopol as a gel base. This formulation has a viscosity contribution to the product adhesiveness, reflecting the importance of product rheology. This formulation imparts the release of the drug at the site of absorption, which may result in a higher concentration of drug at the local site. Hence, based on obtained results, it is concluded that the formulation $0.9 \%$ carbopol and sodium carboxy MC was envisaged as an optimized formulation and drug released for an extended period i.e. over and above $50 \%$ percent release of drug was up to $12 \mathrm{~h}$ this may lead to better patient compliance. This In-situ gel of linezolid could be a potential delivery system for clinical testing in periodontitis. Further, linezolid is a new class of antibiotics, which has clinical use in the treatment of infections caused by aerobes and anaerobes susceptible organisms' methicillin and vancomycin-resistant.

\section{ACKNOWLEDGEMENT}

The authors are thankful to Kemwell biopharma Pvt. Ltd. Bangalore, for providing gift sample of pure linezolid drug and all other chemicals with facility for research by Sri Adichunchanagiri College of Pharmacy, B. G. Nagara, Karnataka.

\section{FUNDING}

Nil

\section{AUTHORS CONTRIBUTIONS}

All the authors have contributed equally.

\section{CONFLICT OF INTERESTS}

The authors declare that the research was conducted in the absence of any commercial or financial relationships that could be construed as a potential conflict of interest.

\section{REFERENCES}

1. Gorle A, Yadav R, Rathod M, Mali P. Formulation and evaluation of in-situ gel containing ciprofloxacin hydrochloride in the treatment of periodontitis. Asian J Pharm Clin Res 2017;10:154-59.

2. World Health Organization (WHO). Antimicrobial resistance: global report on surveillance; 2014. Available from: https://www.who.int/antimicrobialresistance/publications/surveillancereport/en/ [Last accessed on 18 Dec 2020]

3. Zabransky RJ. Linezolid: the first class of a new class of antimicrobial agents. Clin Microbiol News 1 2002;24:25-30.

4. Yoshizawa S, Tateda K, Saga T, Ishii Y, Yamaguchi K. Virulencesuppressing effects of linezolid on methicillin-resistant staphylococcus aureus: possible contribution to early defervescence. Antimicrob Agents Chemother 2012;56:1744-8.

5. Farahamed A, Sayar F, Tehrani RM, Eshfahani BJ. Clinical evaluation of topical application of doxycycline $3 \%+$ ketoprofen
2.5\% gel in chronic periodontitis patients. J Dental Sci 2016;4:178-84

6. Makwanan SB, Patel VA, Parmar SJ. Development and characterization of in-situ gel for ophthalmic formulation containing ciprofloxacin hydrochloride. Results Pharma Sci 2016;6:1-6.

7. Kassab HJ, Thomas LM, Jabir SA. Development and physical characterization of a periodontal bioadhesive gel of gatifloxacin. Int J Appl Pharm 2017;9:31-6.

8. Begum SG, Sekar M. Formulation and evaluation of tinidazole mucoadhesive buccal gels. Int J Pharma Bio Sci 2017;8:48-55.

9. Ahmed MG, Choudhari R, Acharya A. Formulation and evaluation of in situ gel of atorvastatin for the treatment of periodontitis. RGUHS J Pharma Sci 2015;5:53-60.

10. El-Kamel A, Al-Dosari H, Al-Jenoobi F. Environmentally responsive ophthalmic gel formulation of carteolol hydrochloride. Drug Delivery 2006;13:55-9.

11. Ariyana SD, Ervina I, Bangun D. Formulation and in vitro evaluation of alginate-based metronidazole periodontal gel. Asian J Pharm Clin Res 2014;7:223-7.

12. Indian Pharmacopoiea, Government of India. Ministry of health and family welfare. The controller of Publications, Delhi; 1996;1:100-24.

13. Doijad RC, Manvi FV, Malleswara Rao VSN, Prajakta Alsae. Sustained ophthalmic delivery of gatifloxacin from in situ gelling system. Indian J Pharm Sci 2006;68:814-8.

14. Martha J, Gentry N, Keith M, Olsen, Laurel CP. Pharmacodynamic activity and efficacy of linezolid in a rat model of Pneumococcal pneumonia. Antimicrob Agents Chemother 2002;46:1345-96.

15. Wani SUD, Gangadharappa HV, Ashish NP. Formulation, development and characterization of drug delivery systems based telmisartan encapsulated in silk fibroin nanosphere's. Int J Appl Pharm 2019;11:247-54.

16. Wani SUD, Gautam SP, Qadrie ZL, Gangadharappa HV. Silk fibroin as a natural polymeric-based bio-material for tissue engineering and drug delivery systems-a review. Int J Biol Macromol 2020;165:2145-61.

17. Helal DA, El-Rhman DA, Abdel Halim SA, El-Nabarawi MA. Formulation and evaluation of fluconazole topical gel. Int J Pharm Pharm Sci 2012;4:176-83.

18. Biswas GR, Majee SB, Roy A. Combination of synthetic and natural polymers in hydrogel: an impact on drug permeation. J Appl Pharm Sci 2016;6:158-64.

19. Yellanki SK, Nerella NK, Goranti S, Deb SK. Development of metronidazole intravaginal gel for the treatment of bacterial vaginosis: effect of mucoadhesive natural polymers on the release of metronidazole. Int J Pharm Tech Res 2010;2:1746-50.

20. Parhi R, Terapalli BR, Teja B. Formulation and in vitro evaluation of minoxidil topical gel. Turk J Pharm Sci 2014;11:153-62.

21. Kalia S, Singh P, Singh G, Gill NS. Development and characterization of erythromycin estolate emulgel for topical delivery. Int J Recent Adv Pharm Res 2014;4:31-50.

22. Mekkawy A, Fathy M, El-Shanawany S. Formulation and in vitro evaluation of fluconazole topical gels. $\mathrm{Br} \mathrm{J}$ Pharm Res 2013;3:293-313.

23. Hiremath SSP, Fatima SD, Abidabegum N, Vilas G, Mulla JS, Sreenivas SA, et al. Formulation and evaluation of a novel in situ gum-based ophthalmic drug delivery system of linezolid. Sci Pharm 2008;76:515-32. 